\title{
Strategies to Foster Critical Thinking Skills in Nursing Education in Saudi Arabia
}

\author{
Mahaman Moussa ${ }^{1}$ Ahmad E. Aboshaiqah, RN, PhD ${ }^{2}$ \\ Assistant professor in the College of Nursing at King Saud University, Riyadh, Saudi Arabia
}

\begin{abstract}
In most Saudi nursing schools the pedagogy consist of the teacher being the source of knowledge and student are usually having a passive role. The student engagement is very limited and their style of studying consists of memorization. The opportunity to translation of what is learned in the classroom into clinical practice is also limited. The objective of this paper to address the importance of critical thinking in nursing education in Saudi Arabia and its association with competent nursing practice. Strategies to strengthen critical thinking skills in Saudi nursing education are suggested. A systematic review of the literature explores the history and current state of nursing practice and nursing education in Saudi Arabia. The role of critical thinking in nursing education in general and specifically in nursing education in Saudi Arabi a and strategies to enhance critical thinking in nursing education therein are addressed
\end{abstract}

\section{INTRODUCTION}

Ongoing changes in science and technology have contributed to revolutionary changes in every sector of the health care system in Saudi Arabia and around the world. The lack of Saudi nurses qualified to work in this health care environment produced a situation in which the majority of nurses working in the kingdom, especially in major urban areas, are currently expatriates recruited from a variety of countries. However, a global nursing shortage, combined with a concern for nurses with cultural competence in caring for Saudi citizens, has precipitated the need for more indigenous nurses to be educated at the international standard to care for the Saudi population (International Council of Nursing, 2011). Saudi nurses can communicate more effectively with patients, many of whom are not fluent in English. They are better able to meet the health needs of their communities and provide holistic care that reflects patients' religious and cultural values. To meet the international standard of nursing and acquire and maintain international recognition and accreditation, there is a pressing need for Saudi nursing programs to integrate critical thinking into educational outcomes. In nursing, critical thinking has been identified as a valuable educational goal in meeting the challenges of science and technology in the twenty-first century and beyond. In the United States, the National League for Nursing (1987) mandated all nursing program institutes to incorporate critical thinking into the curriculum as part of accreditation requirements.

\section{METHODS}

A systematic data search ( 2001 to date) related to Saudi Nursing education, the impact of critical thinking in nursing education in general and specifically in Saudi as well as suggestions to improve critical thinking in Saudi nursing education were obtained from Saudi health care database, Saudi health journal, and web search using the proQuest, Embase, Cochrane Library, CINAHL and Google search. Web search used standard web browsers and the search words Saudi Arabia, nursing, nursing education, critical thinking. A total of 82 articles were identified. Of the 64 qualified articles 51 met the selection requirements. The selection criteria include articles and studies published in English and findings that focused on Saudi nursing education.

\section{NURSING EdUCATION IN SAUdi ARABia}

A brief history of nursing education in Saudi Arabia is summarized in the following section. It begins with the Holy Wars and continues to the present time. Additionally, various levels of nursing education that have existed - and in some cases continue to exist-in Saudi Arabia are examined. This section ends with an overview of the current state of nursing in Saudi Arabia.

\section{A BRIEF History OF NURSING EDUCATION IN SAUDi ARABIA}

${ }^{1}$ Corresponding Author: mmoussa@ksu.edu.sa 
The roots of health care in the Arabian Peninsula can be traced to a single individual, Rufaida Al-Asalmiya, who provided care for soldiers during the Holy Wars (Aldossary \& Barribal, 2008). At this time, women already had significant experience in providing care as many were traditional healers and were skilled as the nurturing heads of families (Aldossary \& Barribal, 2008). Significant documentation of this period exists as evidence for how the practice of nursing was carried out by Rufaida Al-Asalmiya and others (Miller-Rosser, Chapman, \& Francis, 2006, p. 23).

Thus, nursing was very well defined up until about $632 \mathrm{AD}$, but from this time forward, it was rarely referenced in Arabic texts until the latter portion of the nineteenth century (Miller-Rosser, et al., 2006). However, because of the increase in demand for healthcare, there has been a renewed interest in Nursing. According to AlYami and Watson (2014), formal nursing education began in 1954 with a 1 - year program. The first Bachelor of Science in Nursing (BNS) was established in 1976. Initially limited to women, Saudi universities have recently offered male and female BNS courses (AlYami \& Watson, 2014, p. 11). While King Saud University offer Masters' programs in nursing to both male and female students, international scholarships offered by governmental organizations enable Saudi nurse leaders and educators to study abroad at Bachelor, Master and PhD levels (AlYami \& Watson, 2014).

Even though literature have shown a long history of nursing practice in KSA, there is however no evidence on critical thinking concepts such as analysis, inference and or interpretation being integrated in the curriculum.

\section{LEVELS OF NURSING EDUCATION}

The move toward professionalization of nursing in the Kingdom began with the introduction of nursing certificate programs in 1958, junior nursing programs in 1965, and the opening of the first Junior College courses in 1992 (Aldossary \& Barribal, 2008). The Saudi government supported an increase in the use of science and technology and westernization of the healthcare system to a limited extent, wanting to "embrace those aspects which were beneficial to their society... [while] discarding those which threaten it" (Simpson, 2002, p. 14). In this way college degree programs were carefully instituted with a Bachelor of Science in Nursing (BSN) first being offered in 1976, followed by a Master of Science in Nursing (MSN) program in 1987. (Aldossary \& Barribal, 2008). Availability of nursing programs has continued to increase; however, the number of Saudis applying to all levels of nursing education programs has actually dropped (Miller-Rosser, et al., 2006). Although a concern, this is comparable to the pattern of enrollment in nursing education in the United States, which declined as other opportunities became available-especially to women.

\section{NURSING EDUCATION IN SAUdi ARABIA TODAY}

While there are a number of entry levels into nursing for Saudi citizens today, nursing education enrollment was dominated by the Health Institutes, which do not exist anymore- The challenge today is to enroll enough Saudi nursing students at the standard of General Nurse based on the definition of the International Council of Nurses. This will not only increase the quality of patients 'health care but it will also help Saudi nursing programs to meet their goal of educating enough Saudi nurses to address the growing need in health care in the kingdom. Even though significant progress has been made in this regard, nursing programs are currently still unable to meet the health care demands of Saudi citizens. Factors such as student recruitment and retention as well as a shortage of qualified nursing faculty continue to be barriers in Saudi nursing education and nursing practice, resulting in a continuation of employment of a large number of expatriates in the nursing work force.

\section{The State and Status OF NURSING In SAUdi Arabia}

Saudi nursing education is evolving and continues to play a vital role in the health care system as evidenced by the significant increase in number of Saudi Nurses, which represented only 9\% of the total nursing workforce in 1996; 17\% in 1999; 18\% in 2003; and 29\% in 2004 (Central Department of Statistics, 2004; Gray, 1992, pp.25-29; Marrone, 1999, pp. 9-11). Moreover, standards have been set by Saudi healthcare providers to meet the global vision in nursing education. Standards include: (a) improving competency in Saudi nurses through proficiency in both knowledge and skills; (b) promoting critical thinking to meet the new health care challenges and (c) supporting Saudization policy to increase the number of Saudi nurses in practice (Simpson, 2002; Simpson, Butler, Al-Somali, \& Courtney, 2006).

The availability of free medical care to all Saudi citizens and the positive health outcomes have made Westernized nursing practice much more acceptable. However, more effort is needed to make nursing a more suitable profession for young Saudi menand women (Simpson, 2002, p. 14). Due to a number of factors, many people are still reluctant to fully embrace the nature of modern nursing. Reliance on methods used in the past has also been pervasive in 
nursing education (Aldossary \& Barriball, 2008). Nursing education throughout the world was for many years focused on teaching about diseases and disease processes and curing the symptoms of illness. Unfortunately, this downstream approach to health care, also adopted in Saudi Arabia, does not prevent people from getting diseases, is not cost effective and is not promoting the nation's health. The disease-oriented paradigm has been found to have significant flaws, so the nursing education community in the United States (US) and other Western countries has adopted more of an upstream approach that focuses on health promotion and disease prevention. These programs embraced a primary care focus which incorporated the role of advanced practice nurses educated at the Master of Science (MSN/NP) and Doctorate of Nursing Practice (DNP) programs. Nursing programs in Saudi Arabia have also begun to adopt this focus which resulted in the development of many graduate level nursingspecialties at King Saud University.

Nursing programs in Saudi Arabia have also become more oriented towardstraining nurses to focus on the family model of care as opposed to focusing on the individual patient (Almalki, Fitzgerald \& Clark, 2011, pp. 304 - 311). At the same time, specialty areas such as community health and mental health nursing were developed at King Saud University. This orientation is both a reflection of the traditional Saudi culture and the present push of nursing education (Brown, 2006, pp. 83 - 88).

In the twenty-first century patients' needs are more complex and the healthcare system has also become more complex. To meet these challenges, the pedagogic strategies used in Saudi nursing education have evolved to include leadership, research and evidence-based practice as well as health policy, all of which facilitate the preparation of Saudi nurses to achieve the international standard and promote the level of competency required to provide safe and quality care. Hospitals are being constructed within this paradigm (Brown, 2006) and families are encouraged to be members of the care-taking team.

Movement from the individual to the family-oriented model should make it easier for nursing programs to recruit more young women and men to the field of nursing. However, the strength of the family structure in Saudi Arabia also serves as a barrier to the recruitment of more young people into nursing. Because family and friends are so important in Saudi culture, young people may be strongly influenced in their selection of a profession. Given that the nursing profession has not had prestige in Saudi Arabia, young men and women who choose nursing as a profession may be looked down upon by some Saudis (Simpson, 2002). This serves as a barrier to entering the nursing profession. And, although the number of native Saudis in the nursing workforce continues to grow slowly, the latest figures indicated that only 22\% of the nursing workforce in Saudi Arabia is native (Aldossary \& Barriball, 2008)

\section{The Role Of Critical ThinkING IN NURSING EdUCATION}

The concept of critical thinking has been used in the field of education for many years. Critical thinking has been described in a number of ways and John Dewey has been considered by many to have been the original impetus for critical thinking in education (1916). Because of the wide range of definitions of critical thinking, in 1987, the American Philosophical Association requested that one of the main writers in the area of critical thinking lead a systematic inquiry regarding critical thinking and develop conceptual definitions and guidelines for other scholars. This inquiry was called the Delphi Project and the report that followed was titled The Delphi Report (1990). The final definition of critical thinking that was the outcome of this project is: "Critical thinking is the process of purposeful, self-regulatory judgment. This process gives "a reasonable consideration to evidence, contexts, conceptualizations, methods, and criteria" (American Philosophical Association, 1990, p. 2).

Critical thinking involves making judgments about situations, making decisions within a given context, and using available evidence (American Philosophical Association, 1990). Dimensions of critical thinking include both cognitive skills and affective dispositions (American Philosophical Association, 1990). By consensus, the Delphi panel of experts identified a list of six critical thinking cognitive skills and sub-skills. These skills include: interpretation, analysis, evaluation, inference, explanation and self-regulation (American Philosophical Association, 1990, p. 6; Chenoweth, 1998; Facione \& Facione, 1992).

A concern with critical thinking in education is evident throughout the Western tradition of education, beginning with the Greeks. The most recent belief regarding critical thinking isthat specific skills of criticalthinking should be the foundation of education as a whole and that the goal of education should be to foster critical thinking at all levels (Burbules \& Berk, 1991; Siegel, 1988).

Much of the early work in critical thinking tended to focus on lists and taxonomies of what a "critical thinker" should know and be able to do (Ennis, 1962; 1980).Teaching content and skills is of minor importance, if learners 
American Research Journal of Nursing, Volume 1, Issue 1, 2015

ISSN 2379-2922

do not also develop the dispositions or inclination to look at the world through a critical lens (Burbules \& Berk, 1991).

Conflicting perspectives of critical thinking can be summarized as those having an etic perspective- behavior is universal and therefore critical thinking can be learned outside of content-versus those have an emic perspectiveall behavior must be evaluated within a context and therefore critical thinking is content-specific (Burbules \& Berk, 1991; Burbules \& Rice, 1991; Burbules, 1993; Ennis, 1984; Norris, 1992; Paul, 1990).Additionally, Burbules states that "criticality is always social and cannot be done alone" (1993). He notes that education serves as a condition that allows development of critical thinking.

A specific critical thinking is used in clinical situations by nurses and other health professionals. Diagnostic reasoning is a process of determining a client's health status after gathering data and making clinical judgments. Partof this process relies on the process of drawing conclusions from multiple pieces of data such as: presenting signs and symptoms of patients, laboratory testing results, and patient behaviors. It was not until fairly recently that the role of critical thinking was prominently featured in degree and certificate programs. For nurses, values such as compassion, care, knowledge, skills, the ability to prioritize and decision making are important components of a nursing education. Nurses who entered BSN programs in the past were more likely to receive the rudiments of a critical thinking paradigm, but the importance of critical thinking did not become apparent until recent research demonstrated the need for this type of instruction in nursing programs (Turner, 2005, pp. 272 - 277).

Part of the problem may be that "critical thinking is not a method to be learned, but rather a process and orientation of the mind and so includes both the cognitive and affective domains of reasoning" (Simpson, 2002). For many years the skills focus of nursing pushed critical thinking into the background because the importance of critical thinking was not appreciated and it was deemed too difficult to teach. Nursing educators were assured that students would somehow be able to advance in their clinical reasoning on their own — but we have learned that without direction on the critical thinking processes identified by the NLN as necessary for nursing education programs, any progress in clinical reasoning is uncertain at best. Unfortunately, for the patient, there is a need to have someone immediately available who has "the ability to collect, interpret, analyze, synthesize and evaluate data" (Maneval, Filburn, Deringer, \& Lum, 2011, pp. 229 - 233).

To become a professional nurse requires that one learns to think like a nurse. What makes the thinking of a nurse different from a dentist or an engineer? It is how nurses view the patient and the types of problems nurses deal with in practice. To think like a nurse requires that in addition to the content of nursing, the ideas, concepts, and theories of nursing and development of our intellectual capacities and skills are necessary to become disciplined, selfdirected critical thinkers (Lipe \& Beasley, 2004; Scharenman, 2000, PP. 1)To think like a nurse means to think critically about praxis.

Lives depend on competent clinical reasoning. It is a moral imperative for health care providers to strive to monitor and improve their clinical reasoning and care related judgments (Facione \& Facione, 1997; Facione \& Facione, 2008 , p. 1). Agencies responsible for the accreditation of professional training programs and for the oversight of health care delivery have mandated the need to demonstrate competence in clinical reasoning in health care clinicians and students. Initiated at a meeting of the United States Governors in the late 1980s, educational directives to teach and assess critical thinking and problem-solving have become persistent (Ackerman, Rinchuse, \& Rinchuse, 2006, pp. 133 - 140).

In previous years educators were certain that students and novice clinicians would spontaneously develop clinical reasoning...but we have learned that without a direct focus on the critical thinking processes used to interpret, analyze, evaluate, infer, and explain what is going on, development and improvement of clinical reasoning is not a certain outcome.

In the United States, the National League for Nursing (NLN) - the accrediting body for nursing - has developed guidelines for critical thinking skills to be incorporated into nursing education at all levels and specific content areas to be covered in baccalaureate nursing education programs. These are outlined in the Table below: Critical Thinking Skills and Nursing Content Areas Identified by the NLN. 
American Research Journal of Nursing, Volume 1, Issue 1, 2015

ISSN 2379-2922

Table1. Describing Critical thinking Skills and Nursing Content Areas Identified by the NLN

\begin{tabular}{|c|c|}
\hline Critical Thinking Skills & Nursing Content Areas \\
\hline $\begin{array}{l}\text { Interpret: Ability to recognize, classify \& describe the } \\
\text { significance of data } \\
0 \quad \text { Ask relevant questions and explore ideas } \\
\circ \quad \text { Validate data } \\
0 \quad \text { Recognize issues and concerns }\end{array}$ & $\begin{array}{ll}\text { Research } \\
\circ & \text { Identify topics } \\
\circ & \text { Review/interpret research } \\
\circ & \text { Use research in clinical practice }\end{array}$ \\
\hline $\begin{array}{l}\text { Analyze: Ability to identify the intended and inferential meaning } \\
\text { of, and relationships among, data } \\
\text { o Interpret evidence } \\
\text { ○ Consider viewpoints/Recognize assumptions } \\
\text { ○ Identify missing information }\end{array}$ & $\begin{array}{ll}\text { Legal/Ethical } \\
\circ & \text { Act as a client advocate } \\
\circ & \text { Maintain client privacy } \\
\circ & \text { Apply legal and ethical standards to client care } \\
\circ & \text { Uphold ethical principles }\end{array}$ \\
\hline 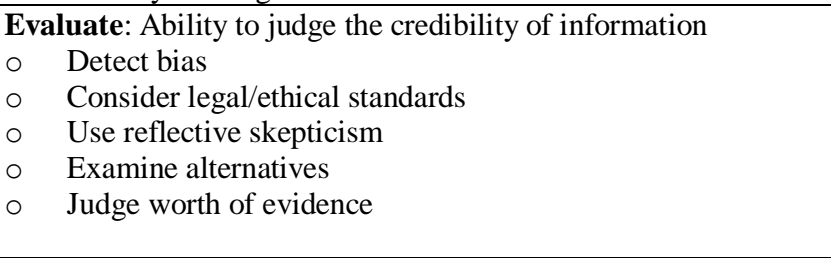 & 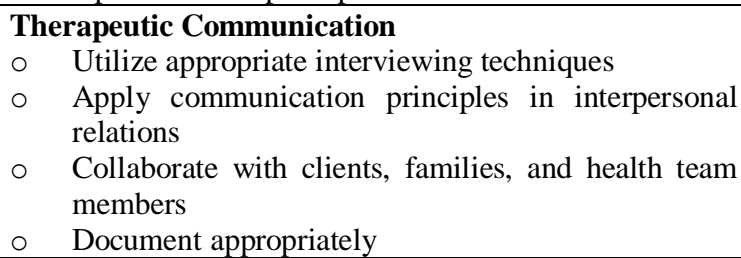 \\
\hline $\begin{array}{l}\text { Infer: Ability to derive reasonable conclusions from the evidence } \\
\circ \\
\circ\end{array}$ & $\begin{array}{ll}\text { Health Care Systems } \\
\circ & \text { Utilize resources } \\
\circ & \text { Consider third-party payer issues } \\
\circ & \text { Manage client care within context of practice setting }\end{array}$ \\
\hline \multirow[t]{5}{*}{$\begin{array}{l}\text { Explain: Ability to justify the results of reasoning activity based } \\
\text { on cogent arguments } \\
\circ \quad \text { Determine outcome attainment } \\
\circ \quad \text { Revise plan } \\
\circ \quad \text { Identify client's perception of results }\end{array}$} & $\begin{array}{ll}\text { Cultural/Spiritual Considerations } \\
\circ & \text { Considers client perspectives } \\
\circ & \text { Solicits client opinions } \\
\circ & \text { Demonstrate flexibility in approach to client care } \\
\circ & \begin{array}{l}\text { Recognize the impact of cultural diversity and } \\
\text { spirituality on health care issues }\end{array}\end{array}$ \\
\hline & \begin{tabular}{ll}
\multicolumn{2}{l}{ Leadership/Management } \\
$\circ$ & Delegate health care responsibilities appropriately \\
$\circ$ & Apply appropriate principles of motivation \\
$\circ$ & Initiate staff development \\
$\circ$ & Management conflict appropriately
\end{tabular} \\
\hline & $\begin{array}{ll}\text { Quality Improvement } \\
\circ & \text { Participate in risk management } \\
\circ & \text { Identify variations and institute change } \\
\circ & \text { Uphold standards }\end{array}$ \\
\hline & $\begin{array}{ll}\text { Health Promotion/Illness Management } \\
\circ & \text { Identify risk factors } \\
\circ & \text { Intervene to reduce risk and promote health } \\
\circ & \text { Set priorities } \\
\circ & \text { Identify safe practice }\end{array}$ \\
\hline & $\begin{array}{ll}\text { Client Education and Empowerment } \\
\circ & \text { Use creative teaching approaches } \\
\circ & \text { Apply principles of teaching and learning } \\
\circ & \text { Respect and adapt to individual learning styles } \\
\circ & \text { Promote client autonomy }\end{array}$ \\
\hline
\end{tabular}

Adapted from: NLN Bulletin, Critical Thinking in Clinical Nursing Practice - RN Information Bulletin, OTACHI880501P, pp. 24.

\section{Skills of Critical Thinking}

Certain skills are important for effective critical thinking. These skills are applied to patient care through the framework called the Nursing Process. The five skills that are needed are: 
$>$ Interpretation - the ability to understand and explain the meaning of information or an event.

$>$ Analysis - the investigation of a course of action based on objective and subjective data.

$>$ Evaluation -the process of assessing the value of the information obtained. Is it credible, reliable, and relevant? This skill is also applied in determining if desired outcomes have been reached.

$>$ Inference-based on the first three steps the nurse can apply the skill of clinical reasoning to the problem and derive reasonable conclusions from the evidence.

$>$ Explanation - the ability to clearly and concisely explain one's conclusions. The nurse should be able to provide sound rationale for his/her answers.

Critical thinking is important in nursing primarily because the nurse is the healthcare worker tasked with direct care of the patient (Simpson, 2002). The need to make decisions that will impact the health and safety of the patient is primary the role of the nurse. Nursing education which fosters this ability does not follow only one method; in fact multiple methods can be used to assist students in learning to think critically (Maneval, Filburn, Deringer, \& Lum, 2011; Reese, Jeffries \& Engum, 2010; Simpson, 2002). But currently, "there is no standard, universally accepted, all-inclusive framework or set of criteria by which to describe or evaluate critical thinking" (Kaddoura, 2011, p. 3). While varied definitions and perspectives have been proposed, critical thinking is a process developed through reflection on experiences and knowledge (Petress, 2004). And, a number of activities have been identified as enhancing critical thinking skills, including: case studies, simulations, reflective journaling, questioning, small group interactions, debate, and role-play (Facione \& Facione, 2008; Kaddoura, 2011; Myrick, 2002; Petress, 2004; Simpson, 2002; Simpson, Mulvill, \& Courtney, 2001). Additionally, several instruments to test critical thinking or to guide faculty in instructional activities to enhance critical thinking have been evaluated within the United States and more recently in the United Arab Emirates (UAE) (Kaddoura, 2011; Simpson, 2002; Simpson, Mulvill, \& Courtney, 2001).

In KSA nursing schools the teacher's role is mainly that of a lecturer, the main source of knowledge therefore students are passive learners. This strategy is deprived of critical thinking skills such as the concepts of interpretation and analysis. The students are also having limited clinical experiences thus another critical thinking skill such as inference is lacking. Limited student's engagements in class discussion also continue to be a challenge to their ability to explain even simple concept. In addition cultural influences prevent student from challenging the authority of faculty as well as clinicians in the hospital. All of which constitute a huge handicap in shaping critical thinking skillin KSA nursing education.

\section{Strategies FOR ENHANCING CRITICAL Thinking IN NURSES AND NURSING STUDENTS IN SAUDI ARABIA}

According to Simpson (2002), it is important to differentiate critical thinking from other types of mental processes which may, at first, seem to be synonymous. Simpson (2002) contends that critical thinking is not the same as problem solving, decision making or even creative thinking. In problem solving, the nurse is not asked to "raise questions about and critique the solutions" (p. 23); decision making is concerned with clinical application (p. 24); and creative thinking often takes a "leap of faith" approach that is not a function of critical thinking (Simpson, 2002, p. 25). Critical thinking requires that the nurse is able to look at a situation, devise possible solutions to the presented problem, and then evaluate which will generate the best outcome when applied to the specific situation (Simpson, 2002, p. 25). This level of thinking is being taught in nursing education programs in the West and it needs to be integrated into nursing education programs in Saudi Arabia.

A great deal of research has been done regarding different methods of teaching critical thinking in different types of programs. Nursing educators have developed a variety of methods to teach criticality. Among those are problembased learning (PBL), experiential education/learning, active learning, the case study method, brain-targeted teaching Rinne, L., Gregory, E., Yarmolinskaya, J. \& Hardiman, M., 2011), group discussion, student-centered teaching, concept mapping, and simulation. All of these approaches can be used to teach nursing students to think critically, but determining which would be best suited for BSN nursing education in Saudi Arabia is an educational conundrum.

Determining the best-suited methods for teaching nursing students to think critically in Saudi Arabia requires consideration of past methods of teaching used in the kingdom (Simpson, 2002). Nursing educators need to 
understand how to connect old methods of teaching with the new methods used to enhance critical thinking and to assure that new methods are appropriate for Saudi culture.

Simpson (2002) evaluated the use of different types of critical thinking pedagogy and their appropriateness when used in nursing education programs in Saudi Arabia as part of her dissertation. Methods evaluated included questioning, small group work, debate, role-play and reflective journaling (pp. 31-38). Questioning or the Socratic Method has been used since the early Greek era. Socrates aimed to teach a subject by making student think about the questions that arose when they were considering the subject. This method is familiar to students in Saudi Arabia because of its basis in that region of the world (Simpson, 2002, p. 31).

In small group technique, students are encouraged to look at an issue while each member of the group is encouraged to think about the problem independently and with other students in the group; then the students go back to the larger group with their thoughts for critical analysis by all members of the class (Simpson, 2002, pp. 35-36). This technique has been used by medical and nursing students for many years during clinical training. The difference here is that students are asked to think critically and ask questions about the approaches presented by other groups. The small group method is very similar to debate, with the primary difference being that in debate students are asked to look at a number of known solutions to a problem and determine which of them is the best for the situation via presenting the pros and cons of the solutions (Simpson, 2002, p. 36).

In role-play, students are placed in situations that simulate reality and asked to act out what they would do in the given situation. Other students are tasked with critically evaluating the responses (Simpson, 2002, p. 37).

The final critical thinking method evaluated by Simpson was reflective journaling (2002, p. 38). She reported that students were asked to journal about their clinical experiences and review their thoughts and actions. This activity allowed students to reflect not only on their own thinking, feeling and behavior but to also reflect on their observations of professional nurses and doctors from the perspective of practices that they were being taught (Simpson, 2002, p. 38).

Reflective journaling has been used widely in the United States over a number of years. Being able to capture some of these concepts and experiences and apply them to Saudi Nursing students would provide an interesting comparison and insight into similarities and differences across cultures.

The methods that Simpson evaluated are a part of the different techniques that have been used successfully in other countries. Many revolve around problem-solving exercises, within a group setting that allows a group of students to evaluate each other's thinking processes. The success or failure of these various techniques was related to the cultural perspective and comfort of various students.

In an earlier study, Simpson, Mulvill and Courtney (2001) used a criteria-based critical thinking tool to improve teaching effectiveness in nurse educators. The authors concluded that a commercial critical thinking instrument, even when translated into Arabic was inappropriate to assess critical thinking skills in Saudi Arabia. However, Kaddoura (2011), using the California Critical Thinking Skills (Form B) translated from English to Arabic, found significant differences in critical thinking scores between two groups using a case-based learning intervention with nursing students in the United Arab Emirates.

Since Saudi Arabia is a paternalistic society, which is revolving around the family with strong central male characters, it has been difficult to imbed critical thinking concepts. Nursing students, both male and female, are reluctant to challenge or question authority or provide opinions that differs from the instructors (Simpson, 2002, p. 199). This carries over into nursing practice and very few nurses are willing to challenge the mostly male physicians (Simpson, 2002, p. 199). A major task for nurse educators is to empower Saudi nursing students and enable them to recognize that it is not wrong to question what an instructor, senior nurse or physician has said. The nurse educator's goal is to use methods that prepare students for their future profession and the critical thinking required.

Simpson (2002) acknowledged that teaching methods need to reflect the ingrained aspects of both the culture and the religion which students have been taught since birth. She noted that students were reluctant to use any technique that they believed in any way violated their culture and religion. Therefore, nursing faculty need to use pedagogic approaches that honor culture, religion and family. To this end, nursing educators have used techniques that promote team critical thinking techniques such as group discussion and small group work (Reese, Jeffries, \& Engum, 2010). Simpson found that Saudi nursing students were more comfortable with these techniques because they did not feel that their critique was singled out apart from the group (2002). By utilizing group critical thinking educational 
approaches, nursing educators should have a great deal of success with facilitating critical thinking with Saudi nursing students.

\section{Implication to Nursing Education ANd Nursing Practice}

While earlier studies and reviews addressed Nursing and nursing education in Saudi, this article explored barriers and strategies to integrate more critical thinking in Saudi nursing education. This is one of the first reviews to examine and suggest practical approaches to foster critical thinking into Saudi nursing education and especially to provide a specific comparison through application of a previous study on reflective journaling to it.

Additionally, this review should open up new avenues for research considering the role of critical thinking as a highly valued educational outcome. Besides the comparison of reflective journaling, the literature will be used to develop a tool to evaluate critical thinking in education. This tool will be used to measure the critical thinking in Saudi nursing students, identify barriers and make specific recommendations for improvement. Together with the comparison of reflective journaling, the analysis will identify factors that enhance or inhibit critical thinking and make specific recommendations for improvement.

\section{CONCLuSiON}

The importance of critical thinking to nursing education has been documented in nursing journals for more than two decades (Simpson, 2002, p. 16), but nursing education in some countries has lagged behind those findings. Saudi Arabia and other Arab countries are significant test cases for critical thinking because their cultures are very different from those in the West. Researchers have found that the techniques that work have to be compatible to the culture, religion and beliefs of the region. Through these findings, it is possible to determine the techniques that are more specific to nursing education in Saudi Arabia.

\section{REFERENCES}

[1] Ackerman, M., Rinchuse, D., \& Rinchuse, D. (2006). ABO certification in the age of evidence and enhancement. American Journal of Orthodontics and Dentofacial Orthopedics 130(2), 133-140.

[2] Aldossary, A., While, A., \& Barriball, L. (2008). Health care and nursing in Saudi Arabia. International Nursing Review, 55(1), 125-128.

[3] Almalki, M., FitzGerald, G., \& Clark, M. (2011). The nursing profession in Saudi Arabia: An overview. International Nursing Review, 58(3), 304-311.

[4] Brown, G. (2006). International nursing department: An up close and personal look at Saudi Arabia (Jeddah and Riyadh) history, culture, and healthcare. ABNF Journal, 16(4), 83-86.

[5] Ennis, R. H. (1962). A concept of critical thinking. Harvard Educational Review, 32(1), 161-178.

[6] Ennis, Robert H. (1962). A concept of critical thinking. Harvard Educational Review, 32, 81-111. Reprinted in B. Paul Komisar and C.J.B. Macmillan (Eds.), (1967), Psychological concepts in education. Chicago: Rand McNally and Company, pp. 114-148.

[7] Ennis, R.H. (1980). Presidential address: A conception of rational thinking. In Jerrold Coombs (Ed.), Philosophy of education 1979. Bloomington, IL: Philosophy of Education Society. Pp. 1-30.

[8] Ennis, R.H. (1984). Problems in testing informal logic, critical thinking, reasoning ability. Informal Logic, 6, 3-9.

[9] Ennis, R.H. (1987). A taxonomy of critical thinking dispositions and abilities. In J. B. Brown \&R. J. Sternberg (Eds.), Teaching Thinking Skills: Theory and Practice. New York: W. H. Freeman. 9-26

[10] Ennis, R.H. (1996). Critical Thinking. Upper Saddle River, NJ: Prentice Hall.

[11] Facione, P. A. \& American Philosophical Association. (1990). Critical Thinking: A Statement of Expert Consensus for Purposes of Educational Assessment and Instruction, Recommendations Prepared for the Committee on Pre-College Philosophy (pp. 315-423).

[12] Facione, P. A., \& Facione, N. C. (1992). The California Critical Thinking Disposition Inventory(CCTDI). Millbrae, CA: California Academic Press.

[13] Facione, N. C., \& Facione, P. A. (1997). Critical Thinking Assessment in Nursing Education Programs: An Aggregate Data Analysis. Millbrae, CA: The California Academic Press.

[14] Facione, N. C., \& Facione, P. A. (2008). Critical thinking and clinical judgment. In N. C.

[15] Facione \& P. A. Facione, Eds. (2008). Critical Thinking and Clinical Reasoning in the Health Sciences: A Teaching Anthology (pp. 1-13). Milbrae, CA: Insight Assessment/The California Academic Press.

[16] Gary, R. (1992). Nurse development program. Nursing Administration Quarterly, 16(2), 25-29. 
[17] Gary, R., Marrone, S., \& Boyles, C. (1998). The use of gaming strategies in a transcultural setting. Journal of Continuing Education in Nursing, 29(5), 221-227. International Council of Nurses. (2011). International classification for nursing practice. Retrieved from: http://www.icn.ch/pillarsprograms/international-classification-for-nursing-practice-icnpr/

[18] Kaddoura, M. A. (2011). Critical thinking skills of nursing students in lecture-based and case-based learning. International Journal for the Scholarship of Teaching and Learning, 5(2), 1-18.

[19] Lipe, S. K., \& Beasley, S. (2004). Critical Thinking in Nursing. Philadelphia: Lippincott, Williams \& Wilkins.

[20] Maneval, R. E., Filburn, M. J., Deringer, S. O., \& Lum, G. D. (2011). Concept mapping: Does it improve critical thinking ability in practical nursing students? Nursing Education Perspectives, 32(4), 229-233.

[21] Marrone, S. R. (1999). International perspectives. Nursing in Saudi Arabia: Leadership development of a multicultural staff. Journal of Nursing Administration, 29(7/8), 9-11.

[22] Miller-Rosser, K., Chapman, Y., \& Francis, K. (2006). Historical, cultural, and contemporary influences on the status of women in nursing in Saudi Arabia. Online Journal of Issues in Nursing, 11(3), 8.

[23] Miller-Rosser, K., Chapman, Y., \& Francis, K. (2009). The use of oral testimony when reconstructing nursing history. A Saudi Arabian experience. Singapore Nursing Journal, 36(1), 23.

[24] Myrick, F. (2002). Preceptorship and critical thinking in nursing education. Journal of Nursing Education, 41(4), 154-164.

[25] National League for Nursing(1987). Critical thinking in clinical nursing practice/RN examination. RN Information Bulletin. New York: National League for Nursing. Retrieved http://www.google.com/search?q=NLN+bulletin+critical+thinking\&sourceid=ie7\&rls=com.microsoft:enUS\&ie $=$ utf8\&oe $=$ utf8\&rlz=1I7ADBF_en

[26] Norris, S. P. (1992). The Generalizability of Critical Thinking. New York: Teachers College Press.

[27] Norris, S. P. (1995). Sustaining and responding to charges of bias in critical thinking. Educational Theory, 45(2), $199-211$.

[28] Paul, R. (1983). An agenda item for the informal logic/critical thinking movement. Informal Logic Newsletter, 5(2), 23.

[29] Paul, R. (1990). Critical Thinking: What Every Person Needs to Survive in a Rapidly ChangingWorld. Rohnert Park, CA: Center for Critical Thinking and Moral Critique.

[30] Petress, K. (2004). Critical thinking: An extended definition. Education, 124(3), 461-466. Phaneuf, M. (2008). Clinical judgement-An essential tool for the nursing profession. Retrieved from:http://www.infiressources.ca/fer/Depotdocument_anglais/Clinical_Judgement\%E2\%80\%93An_Essential_Tool_in_the _Nursing_Profession.pdf

[31] Reese, C. E., Jeffries, P. R., \& Engum, S. A. (2010). Learning together: Using simulations to develop nursing and medical student collaboration. Nursing Education Perspectives, 31(1), 33-37.

[32] Scharenman, S. D. (2000). Critical thinking: To think like a nurse. Retrieved from: http://www.cariboo.bc.ca.nursing/faculty/heaslip/nrsct.htm

[33] Simpson, E. (2002). The development of critical thinking in Saudi nurses: An ethnographical approach. PhD, Queensland University of Technology, Queensland, Australia.

[34] Simpson, E., \& Courtney, M. (2002). Critical thinking in nursing education: Literature review. International Journal of Nursing Practice, 8, 89-98.

[35] Simpson, E., Butler, M., Al-Somali, S., \& Courtney, M. (2006). Guiding the transition of nursing practise from an inpatient to a community-care setting: A Saudi Arabian experience. Nursing \& Health Sciences, 8(2), 120-124.

[36] Tumulty, G. (2001). Professional development of nursing in Saudi Arabia. Journal of Nursing Scholarship, 33(3), $285-290$.

[37] Turner, P. (2005). Critical thinking in nursing education and practice as defined in the literature. Nursing Education Perspectives, 26(5), 272-277. 